\title{
2015 Proceedings
}

Fostering the Professional Development of Saudi Female Students: Implications for Educators in Apparel and Textiles Programs in Saudi Arabia

\author{
Sarah G. Alzahrani and Joy M. Kozar
}

Kansas State University, Manhattan, KS

Keywords: Apparel merchandising, Apparel education, Apparel retail industry, Student success.

Women's participation in the Saudi Arabian workforce is only $14.4 \%$; with the unemployment rate for Saudi female college graduates at 54\% (Saudi Central Department of Statistics \& Information, 2010). To reduce the unemployment rate among Saudi women, the Saudi government is now pushing to replace foreign salesmen with Saudi women in its apparel stores to accommodate the large number of unemployed Saudi females; however, this is being done without properly preparing women to succeed in this industry. Thus, the purpose of this study was to identify the skills and knowledge needed for Saudi women to succeed in the apparel retail industry (ARI). This study is essential to develop an apparel merchandising (AM) program for the apparel and textiles (AT) discipline in Saudi Arabia. It is important to prepare Saudi women for new careers in the apparel industry and provide alternative options for apparel and textiles students to choose from besides apparel design and textile science. This study were guided by the following two research questions:

1. What are the skills and knowledge needed for Saudi female students to be qualified for job opportunities within the apparel retail industry in Saudi Arabia?

2. What are the needs and interests of current Saudi students in apparel and textiles programs?

Qualitative data were collected in two phases: (a) the perceptions of industry professionals in Saudi Arabia was explored through interviewing 21 human resource managers and apparel store managers and (b) the needs of students currently enrolled in AT programs were examined through interviewing 17 female students. A semi-structured interview format was utilized with a standard probing technique (Rubin \& Rubin, 2005). The snowball sampling approach was utilized. The saturation concept guided the sampling process, meaning that additional participants were sought out and interviewed until saturation of the data was achieved. Each interview was recorded using the paper-pen approach as none of the participants felt comfortable being audio recorded. At the end of each interview, the researcher read the responses for the participants to ensure the credibility of the data. The data was analyzed by utilizing the word-based technique (word repetition and key-word-in-contexts) as well as by comparing and contrasting responses to each question. Responses for each question were read across all participants. Then, notes for key concepts and themes based on each interview question were taken. The responses were re-read for comparison, noting repetitive words and

Page 1 of 2 
documenting the similarities and differences among participants. This technique was applied for all interview questions. When the key concepts and themes for each question were identified, the responses to the questions were combined to fully explore the research questions (Gay \& Airasion, 2003). The findings of the two phases were combined and compared to identify the knowledge and skills needed to be included in the new AM track in the apparel and textiles discipline in Saudi Arabia.

Industry professionals in Phase 1 believe that (a) the lack of understanding of the employment opportunities available to women in the apparel retail industry and (b) the lack of education and academic preparation for apparel retail positions have hindered Saudi women's success in the apparel retail industry. In Phase 2, it was found that the AT program was not the desired program of study for most students in this study. In addition, it was found that students lack understanding of the reasoning for basic course requirement in the AT major. In terms of what current students in AT in Saudi Arabia need to learn to succeed in the ARI, the findings of this study consist with the literature and the ITAA meta-goals. Participants reported the need to learn soft skills and hard skills related to specialized areas within the AT major. Apparel and textile major knowledge, business knowledge, mathematics, as well as professional skills such as convince skills, communication, commitment, sense of responsibility, teamwork, hard work, English language, lifelong learning, identifying areas of personal weakness and strength, experience, and creativity are found to be essential for the success of Saudi women in apparel retail industry. For AT educators in Saudi Arabia, these knowledge and skills have to be addressed in apparel merchandising program.

The findings of this study will be used in developing the AM track in Saudi Arabia. Many of the courses to be included in the AM track will be new to AT educators; thus, research is needed to further explore relevant topic areas and student learning outcomes for each course. Effective teaching styles which accommodate the needs of Saudi AT students should also be explored. It is worthwhile to examine what assignments or projects are best suited to each course that encourage student participation and engagement. In addition, a related recommendation would be to investigate the implementation of a mass media campaign to inform people about the employment opportunities available in the apparel retail industry in Saudi Arabia, including the role of the ARI in providing employment for Saudi women in general and for AT students in particular. Examining the effectiveness of such campaigns can be useful in recruiting students for the AM track and communicating the benefits of studying in the AT discipline in preparing for careers in the ARI.

Central Department of Statistics \& Information, (2010). Population 2010 (people). Central Department of Statistics \& Information. Retrieved from http://www.cdsi.gov.sa/english/

Gay, L. R., \& Airasian, P. (2003). Educational research: Competencies for analysis and applications. Upper Saddle River, New Jersey: Pearson Educational, Inc.

Rubin, H. J., \& Rubin, I. S. (2005). Qualitative interviewing: The art of hearing data. Thousand Oaks, London, and New Delhi: SAGE Publications. 